\title{
Tratamiento periodístico desde una perspectiva de género de la violencia contra las mujeres
}

\author{
Mg. CPP. 0235 César Augusto Aguirre Chávez \\ aguirre5113@gmail.com \\ https://orcid.org/0000-0002-1546-1972 \\ Universidad Nacional de Piura. \\ Piura - Perú.
}

\section{RESUMEN}

Este artículo tiene como propósito describir el tratamiento periodístico en las noticias sobre violencia contra las mujeres por razones de género. Para una aproximación al objetivo de estudio, se analizó dos diarios de prensa escrita: La Hora y Correo. Para ello, se realizó un análisis de las noticias sobre violencia hacia la mujer desde una perspectiva de género (en los diarios) durante los meses de enero a marzo del 2016 y que estuvieron accesibles a través de la hemeroteca municipal del distrito de Castilla. Estos fueron procesados con el programa estadístico SPSS versión 22. Como parte de los hallazgos se encontró que la violencia física es la más usada por los agresores. También se evidenció que éstas son de carácter sensacionalista para llamar la atención al lector, no existe una investigación de fuentes y en su mayoría son notas que no cuentan con el respectivo tratamiento periodístico.

Palabras clave: violencia contra las mujeres; perspectiva de género; tratamiento periodístico y análisis de contenido 


\title{
Journalistic treatment of violence against women from a gender perspective
}

\begin{abstract}
The purpose of this article is to describe the journalistic treatment in the news of violence against women for reasons of gender. For an approximation to the study objective, two newspapers of the written press were analyzed: La Hora and Correo. For this, an analysis of the news about violence against women from a gender perspective (in the newspapers) was carried out during the months of January to March 2016 and that were accessible through the municipal newspaper library of the Castilla district. These were processed with the statistical program SPSS version 22. As part of the findings, it was found that physical violence is the most used by aggressors. It was also evidenced that these are sensational in nature to draw the attention of the reader, there is no investigation of sources and most of them are notes that do not have the respective journalistic treatment.
\end{abstract}

Keywords: violence against women; gender perspective; journalistic treatment and content analysis

Artículo recibido: 05 octubre. 2021 Aceptado para publicación: 02 noviembre 2021 Correspondencia: aguirre5113@gmail.com Conflictos de Interés: Ninguna que declarar 


\section{INTRODUCCIÓN}

Los medios de comunicación social han jugado un rol importante al momento de visibilizar la problemática de la violencia de género o violencia contra la mujer en nuestra sociedad. Antes, esta problemática social permanecía oculta dentro de la esfera privada o del ámbito familiar.

Con el ingreso de esta temática a la agenda de los medios de comunicación y, por ende, a la agenda de sus audiencias, se contribuyó a despertar conciencia crítica sobre este flagelo que afecta la vida de miles de mujeres. No obstante, la manera como se la viene abordando periodísticamente, consideramos que no es la más adecuada.

En el discurso informativo de los medios, la violencia contra la mujer, en particular la violencia familiar y sexual, así como el feminicidio (homicidio de mujeres por razones de género), no son representados como un grave problema de violación de los derechos humanos, sino como una noticia policial más, como una serie de sucesos individuales y con una fuerte carga de estereotipos de género, que apartan la atención de la audiencia sobre el problema de fondo, es decir, de la violencia contra la mujer, que tiene su origen histórico en la inequidad de poder entre el varón y la mujer.

"Todos los días vemos y escuchamos que las mujeres son constantemente violentadas en la casa, el trabajo o en lugares públicos, sin que hagamos algo para cambiarlo. Las mujeres cercanas a nosotros están en peligro de ser violentadas” (Pizarro, 2013)

"Las niñas y los niños también son objeto de diversas formas de maltrato y violencia. Los hombres sufren lesiones o mueren violentamente a manos de otros hombres." (Pizarro, 2013) Todo ello convierte a la violencia en un grave problema social y de salud pública, con serias consecuencias para el bienestar físico y emocional de todas y todos.

Estas representaciones se muestran a través de los medios de comunicación, lo vemos al momento de prender la televisión o leer un periódico, lo que nos hace ver una problemática latente.

"Se ha perdido la seriedad para la construcción de las notas y por lograr concurrencia de lectores han perdido el sentido de informar a la población los sucesos con profesionalidad y se han evocado a llamar la atención por medio del morbo. (Rodríguez Carcela, 2017) "Se debe cuidar las imágenes que acompañen las notas, respetar a la víctima y siempre se debe incluir un número en el cual deban pedir ayuda”. (Vega, 2017) 
En consecuencia, la meta fue analizar el tratamiento periodístico que se le dio a la violencia contra las mujeres desde una perspectiva de género en los diarios regionales (la hora y correo) durante los meses de enero a marzo de 2016, propósito que se logró a través de tres aspectos: primero, describir la cobertura e importancia que los diarios hacen de este fenómeno; segundo, establecer las características de las fuentes; tercero, identificar las representaciones que se hace de las mujeres y varones involucrados en los hechos.

Así pues, se dio paso al análisis de contenido: técnica de investigación destinada a formular, a partir de ciertos datos, inferencias reproducibles y validas que puedan aplicarse a su contexto (Krippendorff, 1990). En ese sentido, se encontró el uso de estereotipos, prejuicios, desconocimiento de las normas y ausencia de información útil para la formación del público en estas materias.

\section{Representación de la violencia contra las mujeres en los medios escritos}

Luísa Abbott se refiere a los medios como un espejo que refleja lo que la sociedad coloca como imagen educativa sin tomar en cuenta que como medios tienen el poder de hacer buen uso de su poder forjando una idea clara de lo es la violencia contra la mujer. "La prensa no solo documenta las instancias de violencia contra la mujer sino que conretiza los roles que asocian al género".

Los movimientos de mujeres reconocen que la prensa como un lugar crítico para la igualdad de Género así mismo da a conocer que los términos que utilizan tampoco ayudan a ello.

La prensa tiene como deber describir a la violencia contra la mujer de una manera que respete y afirme los derechos humanos, la dignidad de las mujeres, la ocurrencia y la percepción. De tal manera que deben incluir datos específicos de cada región para encontrar la oportunidad de intervenir.

Sin embargo, los medios son los responsables de reproducir los estereotipos lo que aparece en la narrativa como victimización. En la prensa rara vez se presentan como un problema social que involucra injusticia, discriminación donde se ejerce poder y control. Otra forma en que los medios abordan este tema enreda la figura del agresor y ponen llaman a la agredida "la víctima ideal", estereotipan a la mujer con el rol pasivo y desinteresado, abarcando el tema de reforzar su incapacidad. (Abbott, 2016)

Los medios de comunicación tienen como representación a la mujer a través de tres características: 
- Esposa, madre, cuidadora del hogar

- Objeto sexual utilizada para vender productos al público masculino

- Una persona que busca ser bella para los hombres

Todo ello refuerza los estereotipos. Así mismo los discursos de los medios juegan un papel de legitimización de la ideología dominante. (Vallejo, 2005)

La violencia contra la mujer en la prensa es reproducida a través de la publicidad en la que estereotipos sexistas que promueven la violencia por si sola en vez de iniciar una sociedad con igualdad y respeto. En las noticias de igual manera permiten que a la mujer se le reproduzca como una imagen victima e incapaz de defenderse.

Las fuentes de información en su mayoría son instituciones y las mujeres víctimas, la prensa de igual manera fomenta la violencia colocando imágenes o fotografía en la cual la mujer se muestra en mal estado, sumisa.

En la cual se puede concluir de todo ello que la prensa no solo no promueve los derechos de las mujeres, sino que lucran con reproducir la violencia de género. (Montiel, 2014) Los medios de comunicación se basan en relaciones de dominación y subordinación. La identificación de la víctima y del agresor es un tema discutible desde que entra en conflicto las normas éticas generalizadas en el periodismo con la considerada como eficaz medida en la lucha contra la violencia por parte de organizaciones de mujeres expertas en este tema.

"Los periodistas se centran en las aportaciones que provienen de la judicatura y que defienden mayoritariamente el anonimato para el agresor. Las razones de las mujeres radican en que sería motivo de reprobación social, y, por tanto, eficaz para el cambio de conducta, el que la sociedad conociese no sólo el delito cometido por el agresor, sino su identidad, en la medida en que estos individuos, según la investigación, es en la familia en donde despliegan su violencia y peores maneras, comportándose como vecinos ejemplares y correctos compañeros con las personas con quienes trabajan.” (López, 2002)

Maite Rodigou explica que en los medios escritos como la prensa tienden riteradamente a utilizar lo términos equívocos cómo:

- Crimen pasional. 
- Riña y disputa matrimonial.

- Bajos Instintos.

- Crímenes por amor.

- Crímenes de honor.

- Por cuestiones de celos.

Así mismo reflejan en sus imágenes una idea distorsionada de la mujer en su totalidad, centrándose en la mujer como objeto sexual, víctima, figura dominaria. Sin embargo olvidan que en la sociedad exsiten actualmente, muejres jueces, ingeniera, juezas, transportistas, agricultoras, ministras; todo elloes una forma de ampliar el campo de representación y evitar sobredimensiones. (Rodigou, 2007)

La prensa en la difusión de la violencia doméstica a sesgado este problema; en muchos diarios las secciones es importante y básica, anteriormente todas las noticias aparecían en la seccion social y no en la de sucesos por lo que empezó a verse a la violencia como un acontecimiento ocasional, coyuntural y accidental cuando en realidad lo que necesitaba más credibilidad, objetividad, y fiabilidad a su contenido.

El contenido de las noticias estaba condicionada todo lo que se transmitía era el acto de la violencia y la ley, y daba información más de dónde provenía la violencia y cómo se desarrolla el acto y aunque las noticias no se ubicaba en suscesos la información se transmitíaen forma de crónica de sucesos no cual no permitía visualizar la reflexión en caso se dé otro acto de violencia. (Gutierrez, Notario, Martinez, \& Monereo, 2009)

\section{El rol de los medios de comunicación en la erradicación de la violencia contra la mujer}

Según Ramírez Alvarado; los medios de comunicación se han convertido en agentes de educación formal, no formal e informal en nuestra sociedad por lo que los propietarios y responsables de los medios con los que trabajan para ellos deben considerar ser conscientes de su gran responsabilidad en su acción educadora actual y deben afanarse a transmitir valores importantes como la igualdad de las personas se por el sexo, religión y posición económica, etc.

Los que se encarguen de luchar por ello estarán contribuyendo a erradicar la violencia en general y contra las mujeres en particular, y por ende colaborar en la construcción de una sociedad más justa la frase que apela a los medios de forma radical es "El ojo que mira, y la mente que interpreta". La realidad que se observa es mínima, el interés de la 
información se centra en parte de la vida íntima que se percibe, los elementos se configuran en un conocimiento parcial y limitado.

Los medios de comunicación juegan un rol importante para conocer la realidad de la violencia contra la mujer y para ello es necesario eliminar toda serie de mitos y creencias puesto que ellas son limitantes.

Bertillón dijo, "Sólo se ve lo que se mira y sólo se mira lo que se tiene en la mente" para referirse a los estímulos que llegan al cerebro los que se transforman en datos y se relacionan para ser interpretados.

La capacidad sensorial y de percepción es el factor que determina el conocimiento. (Ramirez Alvarado, 2003)

Todo lo que es interesante es noticia, pero no todo es considerado como información. Los medios de comunicación desempeñan una función importante en el conocimiento de la realidad, los sucesos que acontecen y los transforman en noticia determinan la imagen y la conciencia de la realidad.

La imparcialidad es uno de los objetivos que debe tenerse a la hora de elaborar una noticia ni en favor ni en contra. Sin embargo, la neutralidad conlleva cierta parcialidad. Y por ende es lo que sucede en una sociedad patriarcal en relación con los temas sobre la violencia contra las mujeres, en la existe parcialidad porque no hay neutralidad.

Se ha debatido la capacidad de los medios de comunicación para crear opinión, destacando tres posiciones en este sentido:

"Los que afirman sin ningún género de dudas que la capacidad de los medios y el formato de la información es tal que, de una manera u otra, sucumbimos a sus efectos hasta en lo que es la opinión, y los que creen que no es así, que las personas no se dejan influir por las opiniones de los otros o que ante una diversidad de medios e informaciones sería muy difícil influir en un sentido $\mathrm{u}$ otro. Luego existe una tercera posición intermedia que afirma que sí influyen, pero no con relación a cualquier tema ni sobre todas las personas.” (Ramirez Alvarado, 2003)

Sea cualquiera el caso la comunicación influye de forma activa sobre las personas, bien creando opinión o bien arrojando una serie de datos, opiniones y elementos que serán utilizados, tomándolos o rechazándolos, para configurar una opinión individual. 
(Naciones Unidas, 2017) Explica que en los medios la capacitación y la sensibilización de los periodistas y otros profesionales de la comunicación que informan sobre la violencia contra la mujer constituyen prácticas prometedoras, mejoran la calidad de la información y favorecen creando conciencia y comprensión de las causas y consecuencias de la violencia contra la mujer por parte del público en general.

En Nepal, las mujeres periodistas monitorean los actos de violencia doméstica sobre los que se informa en los periódicos e impartir capacitación al personal de los medios de comunicación sobre la violencia contra la mujer, estimulándolos a informar sobre los casos de violencia con sensibilidad respecto de la víctima.

La creatividad de los medios populares para llegar a públicos más amplios. Un ejemplo es: "Un vídeo musical elaborado por Breakthrough, un grupo femenino de derechos humanos de la India, referido a la violencia doméstica y el empoderamiento de las sobrevivientes. Llegó a más de 26 millones de hogares en toda la India y estuvo entre los 10 primeros lugares de las listas musicales del país 380.” (Naciones Unidas y Derechos Humanos, 2017)

El uso de las nuevas tecnologías de la información y la comunicación, como los teléfonos celulares y la Internet pueden ser utilizados de manera adecuada la cual permita difundir ampliamente la información y permitir la interacción entre los interesados de diversos lugares. (Naciones Unidas, 2017)

Para (Toledo \& Lagos, 2017) La producción informativa, es transcendental considerar la baja contribución de las mujeres en las redacciones de los medios y en los cargos de responsabilidad editorial. Además, varios estudios revelan que los valores noticiosos hegemónicos aún corresponden a una cultura machista que impregna las rutinas periodísticas de las salas. También, distintos estudios, en países dan cuenta de la sobrerrepresentación de la violencia y la discriminación contra mujeres y niñas en los contenidos informativos, especialmente los que se transmiten por televisión.

Posibles efectos de la cobertura informativa de los feminicidios han cometido el error de presentar la violencia contra las mujeres como un problema individual/de pareja. Por ello en la cobertura mediática del feminicidio y de la violencia contra las mujeres, se han reconocido cuatro orientaciones:

1. Orientación policial o "solo los hechos" 
2. Orientación que considera que dichos eventos involucran a personas diferentes a "nosotros".

3. Orientación que culpa a las víctimas y/o excusa al victimario

4. Orientación desde el impacto debido a que el perpetrador es identificado según su "normalidad"

La orientación policial o "sólo los hechos" favorecen una visión sensacionalista, donde se destacan datos escabrosos como el número de puñaladas que recibió la víctima u otras particularidades del ataque. Esta orientación es acostumbrada en Latinoamérica, pero también está presente en Europa. En la que hacen los medios hacen referencia a los celos o el uso de drogas o alcohol. (Toledo \& Lagos, 2017)

El tratamiento informativo de la violencia doméstica hacia las mujeres, es un importante historial en el tratamiento de las noticias sobre la violencia hacia las mujeres por razones de género aporta insumos teóricos para la reflexión sobre el sexismo y herramientas para decidir en la inmediatez del trabajo periodístico, en que se considera importante reproducir:

- El peso de las imágenes de género femenino y masculino.

- La urgencia e inmediatez de la información.

- Necesidad de síntesis.

- La búsqueda de referencias para titular.

- La especularidad o dramatismo.

- La tentación del sensacionalismo.

- La necesidad de encontrar fuentes adecuadas. (Rodigou, 2007)

\section{ESTRATEGIAS METODOLÓGICAS O MATERIALES Y MÉTODOS}

Esta investigación se realizó desde un enfoque No Experimental - Ex Post Facto: Es una investigación donde no se manipulan variables, sólo se describirán en un tiempo determinado, cuando el hecho (la publicación) ya se realizó.

Para Sampieri, en su libro "Diseño de la Investigación" define el diseño de investigación no experimental como el que se realiza sin manipular deliberadamente variables independientes, se basa en variables que ya ocurrieron en una realidad sin la intervención directa del investigador.

También es Transversal porque se van a tomar los datos de las publicaciones en un periodo de tiempo el cual está comprendido en el primer trimestre del año 2016, en los 
meses de enero, febrero y marzo. Asimismo, será pura, porque permite incrementar el conocimiento científico. Para Sampieri (2003) la investigación transversal es aquella donde se recolectan datos en un solo momento, en un tiempo único, su propósito es describir variables y su incidencia de interrelación en un momento dado.

De igual forma, la investigación será descriptiva porque se van a explicar cómo se encuentran redactadas estas publicaciones periodísticas y qué enfoque de género le están dando. Según Sabino (1986) “La investigación de tipo descriptiva trabaja sobre realidades de hechos, y su característica fundamental es la de presentar una interpretación correcta. Para la investigación descriptiva, su preocupación primordial radica en descubrir algunas características fundamentales de conjuntos homogéneos de fenómenos, utilizando criterios sistemáticos que permitan poner de manifiesto su estructura o comportamiento. De esta forma se pueden obtener las notas que caracterizan a la realidad estudiada”. (Pág. 51)

Es mixta, ya que es una investigación que no solo permite analizar de manera cuantitativa (cantidad de noticias sobre violencia, número de páginas usadas para estos temas, espacios de redacción y fotografías) sino también cualitativa (tratamiento periodístico de temas de violencia). Tal como lo señala el autor Roberto Hernández. Sampieri en el libro "Metodología de la investigación" (pág. 31) la investigación mixta es un nuevo enfoque e implica combinar los métodos cuantitativo y cualitativo en un mismo estudio.

Además, es propositiva pues se está proponiendo un manual de recomendaciones para mejorar el tratamiento periodístico de violencia hacia las mujeres. Nivel no experimental simple: descriptivo.

En relación a lo anterior, el tipo de muestra que se describe a continuación fue de conveniencia o de selección intencionada debido a la accesibilidad y disponibilidad para su estudio, de modo que esta técnica de muestreo no es probabilística, así que los resultados no se harán generalizados. Esta técnica de muestreo es también útil para documentar que una calidad particular de un fenómeno se produce dentro de una muestra dada.

La investigación está conformada por diarios regionales (La Hora y Correo) durante los meses de enero a marzo de 2016. 
La unidad de análisis fue la nota periodística, esta entendida como una pieza informativa impresa cuya estructura generalmente consta de titular, volada o antetítulo, bajada, lead o entradilla, cuerpo de noticia y fotografía o infografía.

Se hizo un trabajo de categorización y análisis orientado a cumplir los objetivos específicos:

- Para el primer objetivo específico las variables que se analizaron fueron: espacio noticioso, fotografía, tipo de información, número de fuentes citadas, entre otros.

- Para el segundo objetivo específico las variables que se analizaron fueron: titular de la noticia y el desarrollo de la misma.

- Para el tercer objetivo específico referido a elaborar un manual de recomendaciones desde una perspectiva de género para el tratamiento periodístico (en prensa escrita) de las noticas de violencia hacia la mujer se tomó como referencia las "Pautas para el Tratamiento Informativo Adecuado de la Violencia Contra la Mujer en los Medios de Comunicación Social” el Ministerio de la Mujer e Inclusión Social.

\section{RESULTADOS Y DISCUSIÓN}

\subsection{Resultados}

- Ambos diarios contienen noticias sobre violencia contra las mujeres: La Hora (58\%) y Correo (42).

- La fecha que más se emitió más noticias sobre violencia es el mes de febrero con el $36 \%$.

- En las formas de violencia más usadas en diario La Hora fueron la física con el $51 \%$ la psicológica con el $22 \%$ y la sexual con el $23 \%$. En diario Correo las formas de violencia más usada fue la física con el $45 \%$, psicológica con el $28 \%$ y la sexual con el $27 \%$.

- El tamaño y la relevancia de la noticia más usada por el diario La Hora es mínimo de $1 / 2$ de pg. con el $33 \%$ y la de $1 / 4$ pg. con el $22 \%$. Lo mismo sucede en Correo donde el tamaño de página más usado es la breve con el $40 \%$ y la de $1 / 4$ con el $23 \%$.

- En las justificaciones de la violencia se encontró que el $31 \%$ de los documentos se ha dado una violencia por razones que no son por golpiza o violación de conyugue sino más bien son robos y violaciones por personas externas; en un $23 \%$ la mató por celos, $15 \%$ la golpeó por celos, $15 \%$ la golpeó por no atenderlo, $8 \%$ la violó por venganza y $8 \%$ la mató por no tener relaciones sexuales. 
El primer hallazgo de esta investigación corresponde "Tratamiento periodístico de la violencia contra las mujeres desde una perspectiva de género en los diarios regionales (la hora y correo) durante los meses de enero a marzo de 2016".

A1

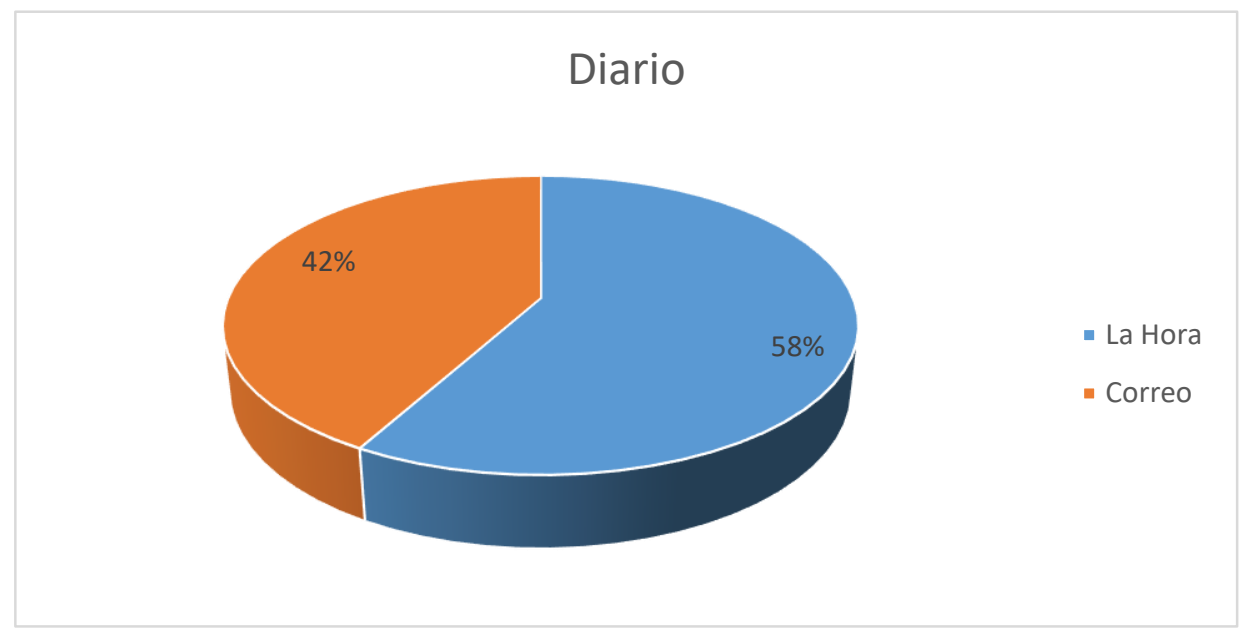

Ante el tratamiento de violencia contra la mujer encontramos que el diario La Hora, con el $58 \%$ y diario Correo con el $42 \%$ de los cuales en su mayoría es diario La Hora quien presenta más contenido de está, recalcando que este diario cuenta con lenguaje coloquial en cuál la violencia es utilizada como tipo de morbo para atraer al público.

B1

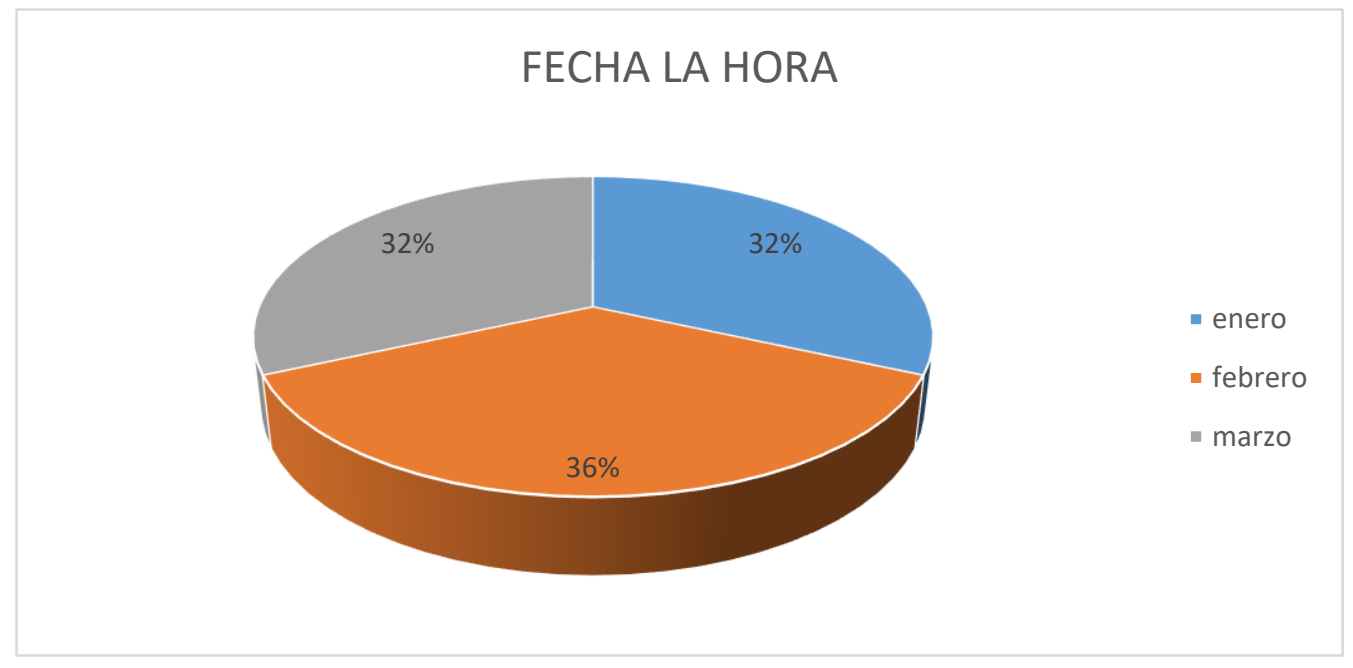

En diario La Hora el mes de febrero cubrió el 36\% cantidad mayor de noticias sobre violencia a la mujer. Y la menor el mes de enero y marzo con igual cantidad $32 \%$. 
B2

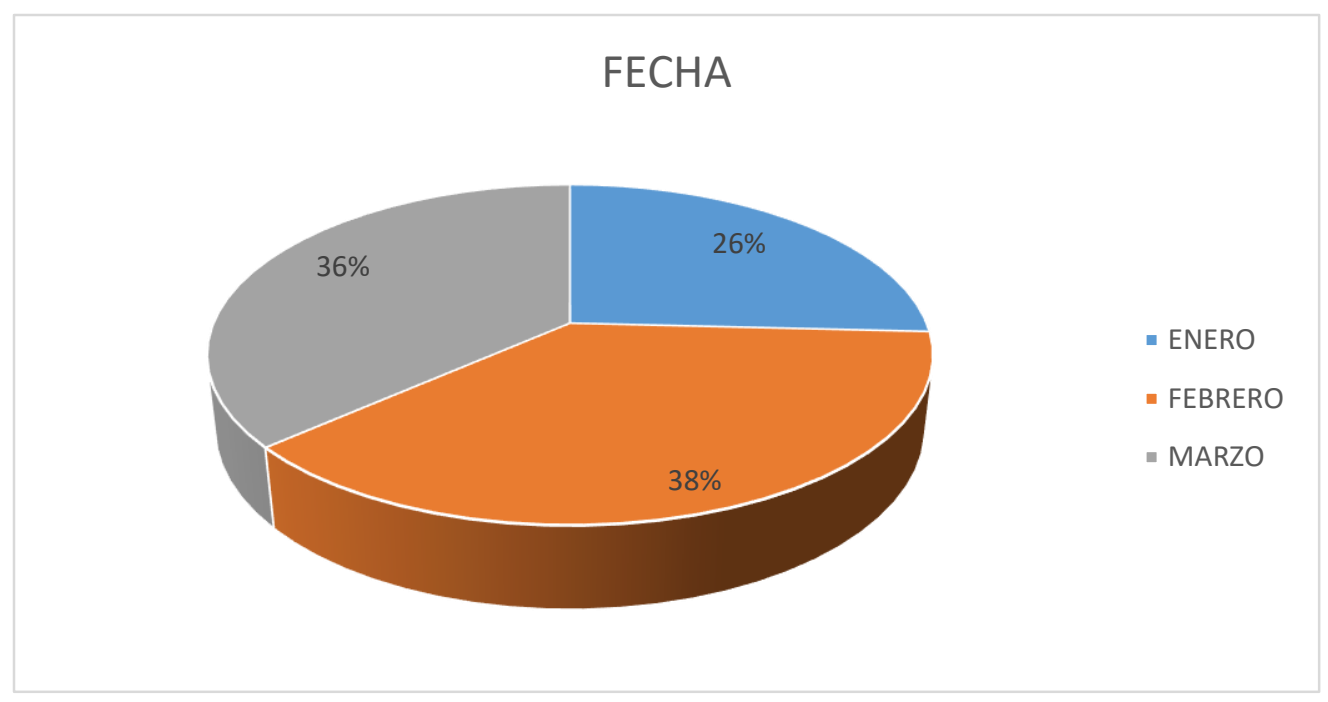

Los meses considerados para la investigación fueron ENERO, FEBRERO Y MARZO del año 2016, por los cuales se encontró que los meses con mayor violencia contra la mujer fue el el mes de FEBRERO 2016 siguiéndoles el mes de Marzo 2016 finalizando con el mes de ENERO 2016.

\section{C1}

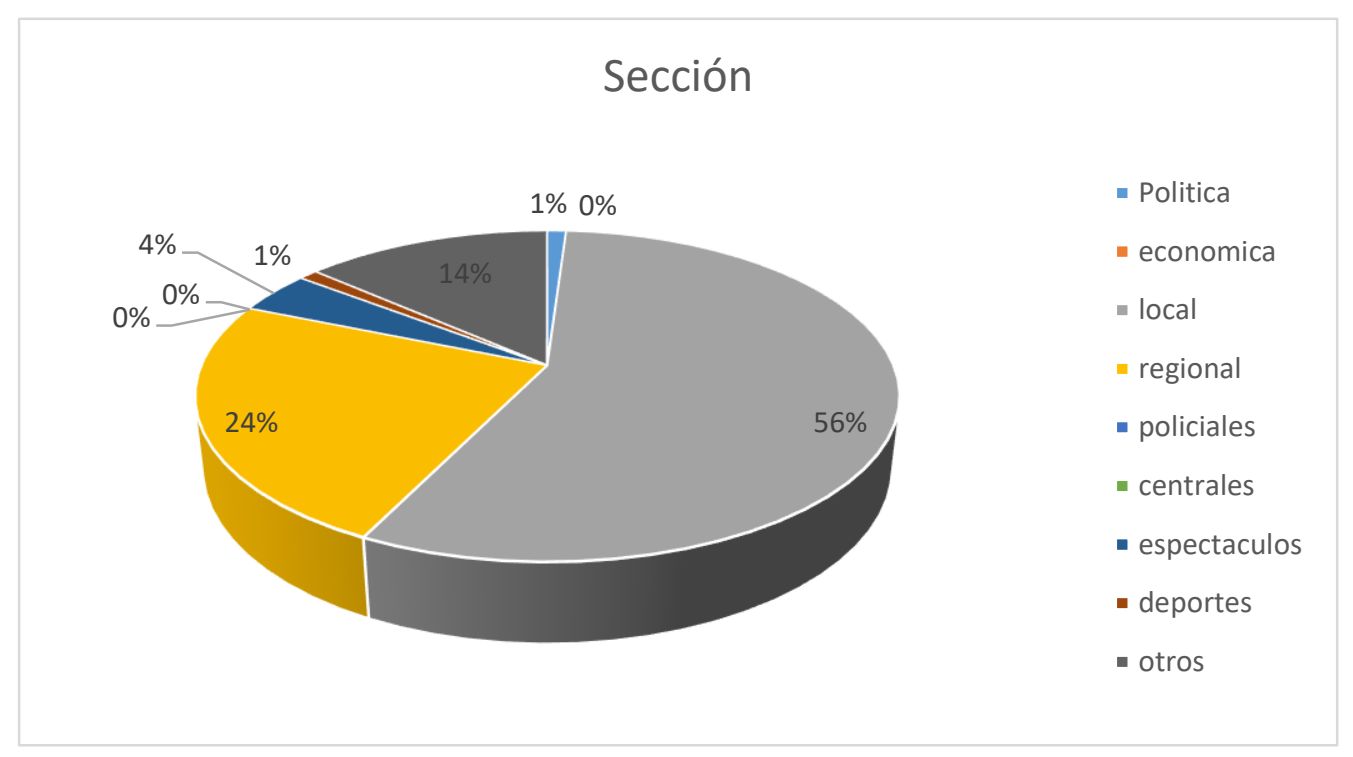

La sección más usada por ambos de ambos periódicos es la local con el 56\% seguida de la regional con el $24 \%$. 
D1

\section{FORMAS DE VIOLENCIA LA HORA}

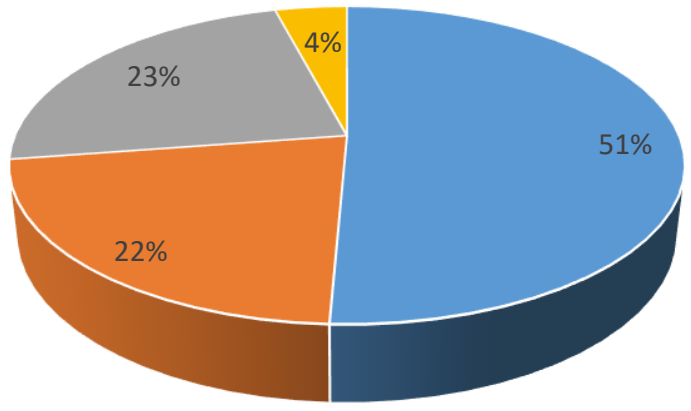

- física

- psicológica

- sexual

- simbólica

En el diario La Hora la violencia 'fisica se dio en un 51\%, luego le sigue la violencia psicológica con $22 \%$ y la sexual con el $23 \%$.

D2

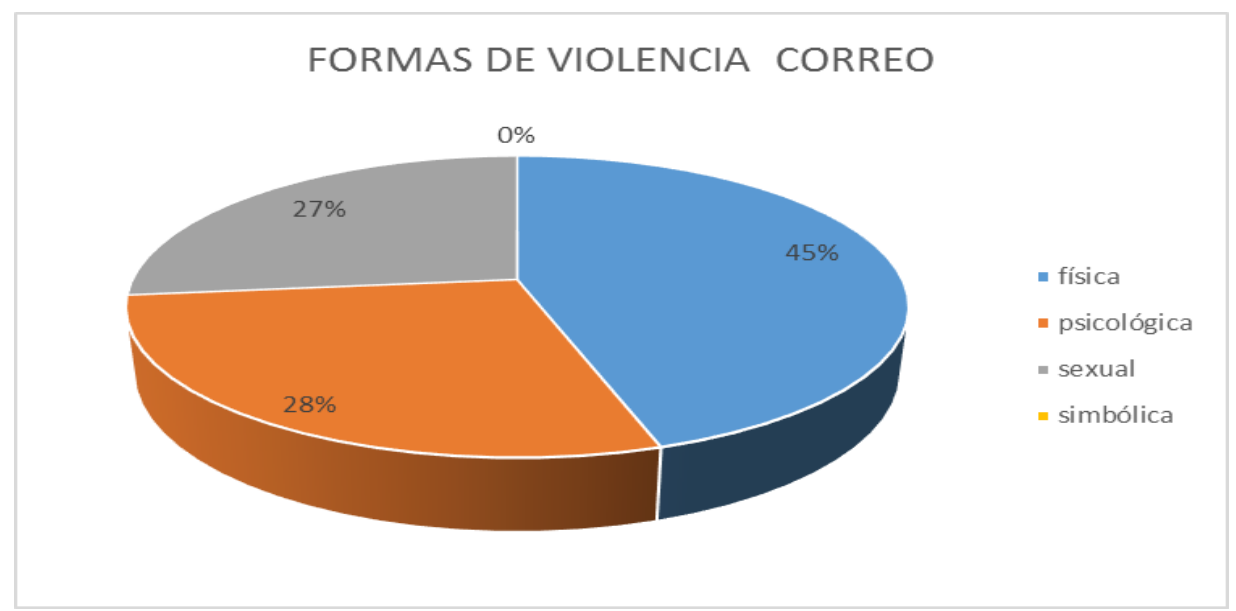

El diario correo tuvo el $45 \%$ de noticias referidas a la violencia física, seguida de la psicológca con el $28 \%$ y violencia sexual con el $27 \%$.

D3

FORMAS DE VIOLENCIA


En las formas de violencia tenemos que en los diarios la Hora y Correo impera la violencia física con el $49 \%$, sea por robo, intento de violación o agresiones físicas.

Le siguen la violencia sexual con el $26 \%$ y violencia psicológica con el $25 \%$ vertientes que van de la mano con la violencia física.

\section{E1}

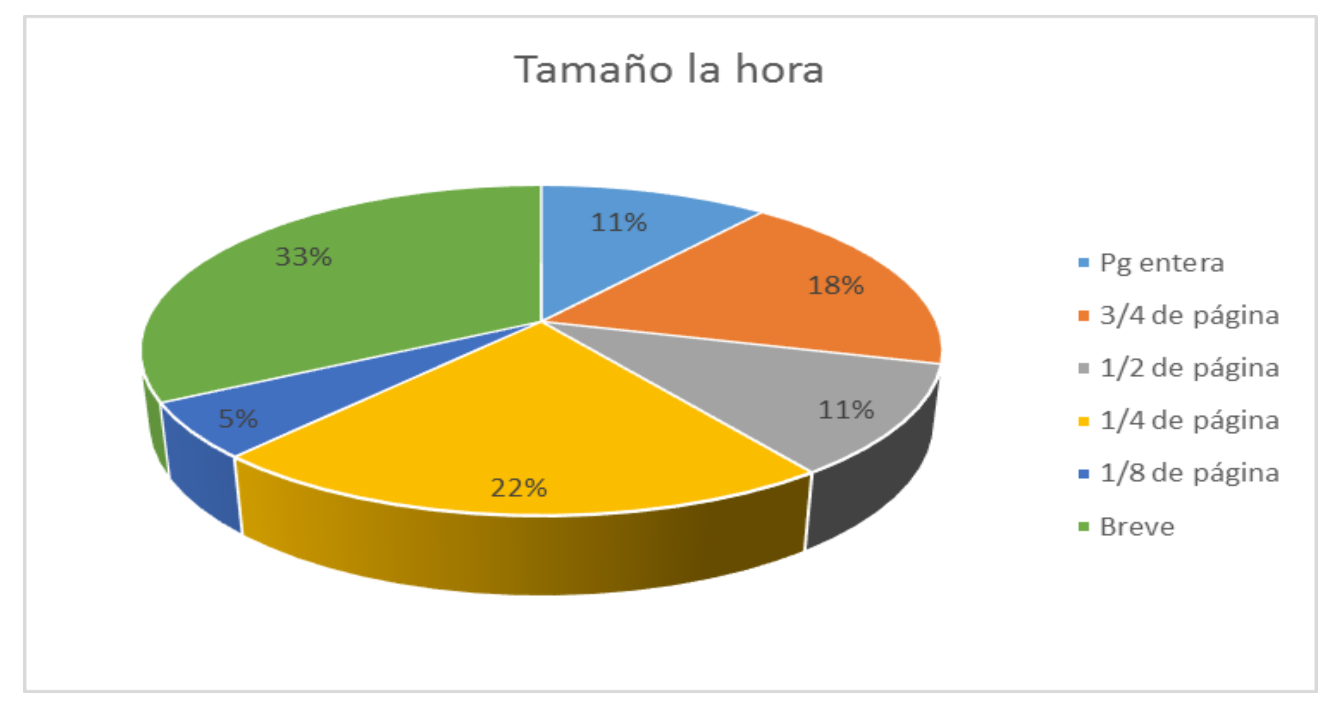

El tamaño de página más usado es por el diario la Hora, con el 33\% le sigue $1 / 4$ de página con el $22 \%$.

\section{E2}

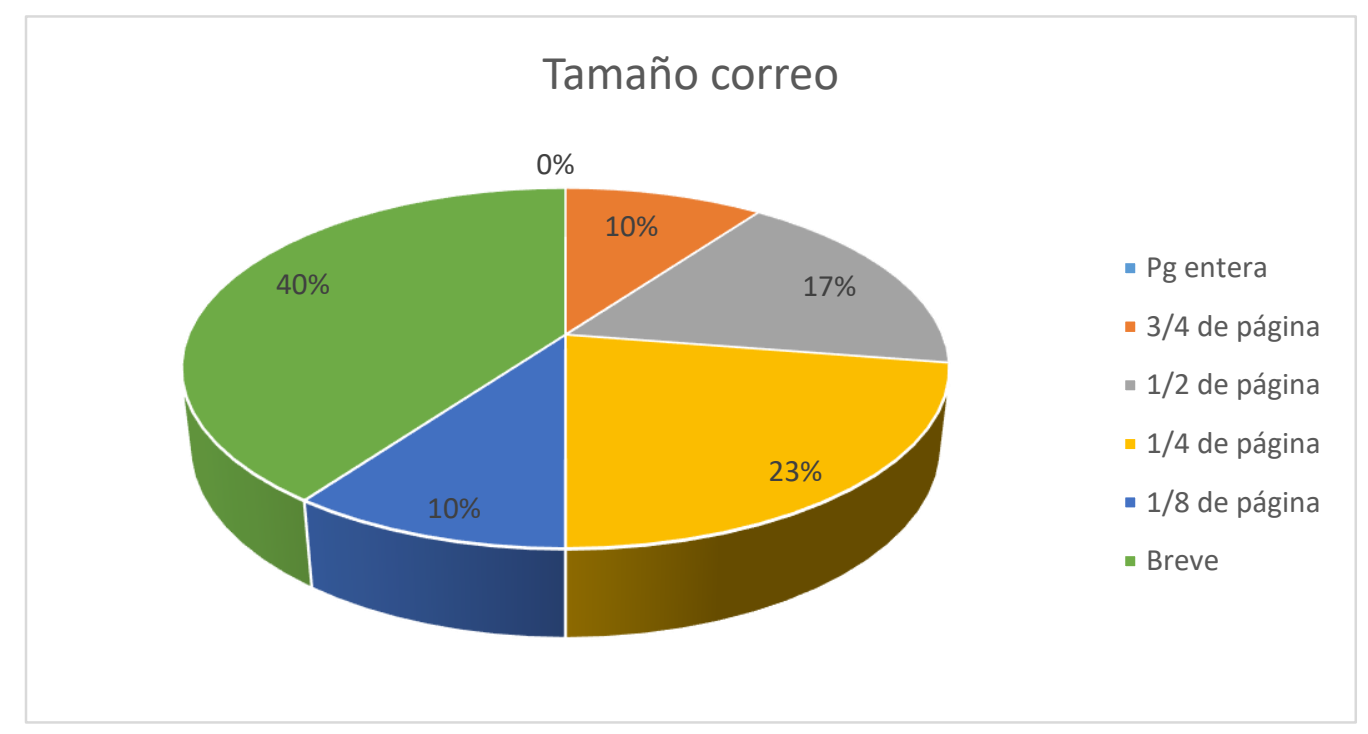

En correo el tamaño más usado la breve con $40 \%$ y la que sigue $1 / 4$ con el $23 \%$. 


\section{E3}

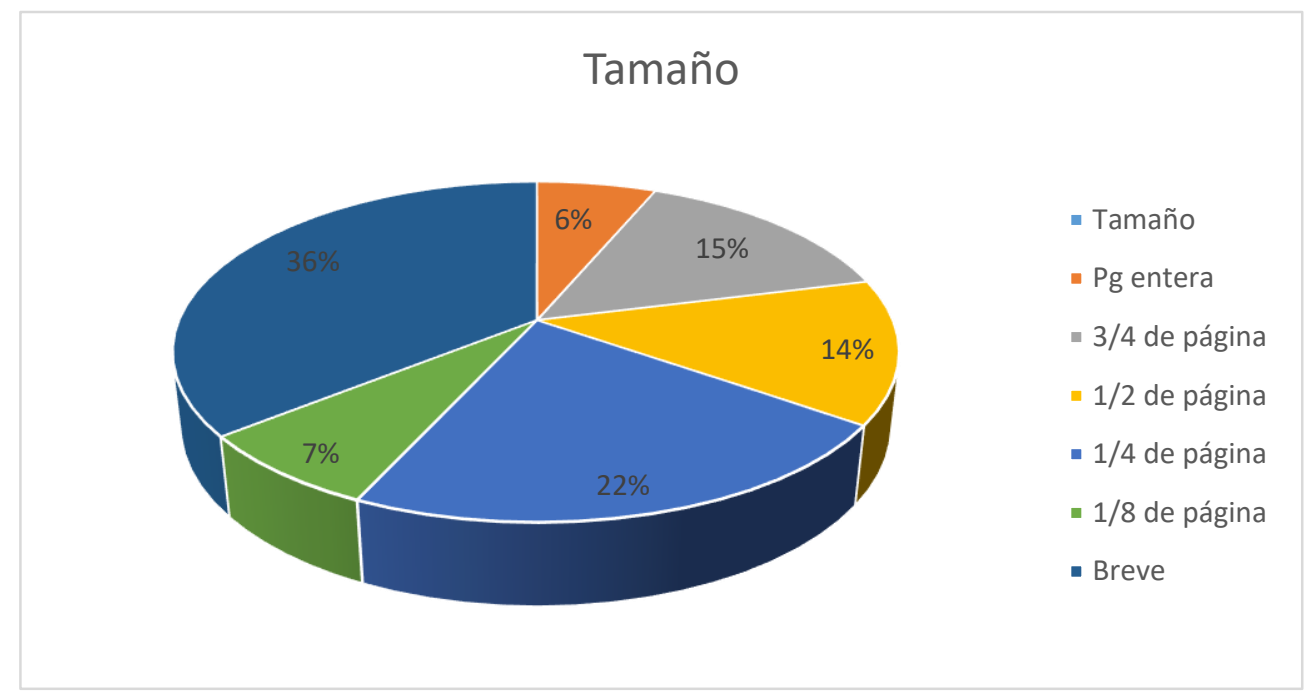

El tamaño de noticia que más se uso es la breve con el 36\% ambos periódicos utilizan este tamaño sólo para dar a conocer noticas rápidas, le sigue la página de 1/4 con el 22\%, Le sigue la $1 / 4$ página con el $15 \%$, y la $1 / 2$ página con el $14 \%$ y por último la página $3 / 4$ con el $7 \%$ y la página entera con el $6 \%$.

F1

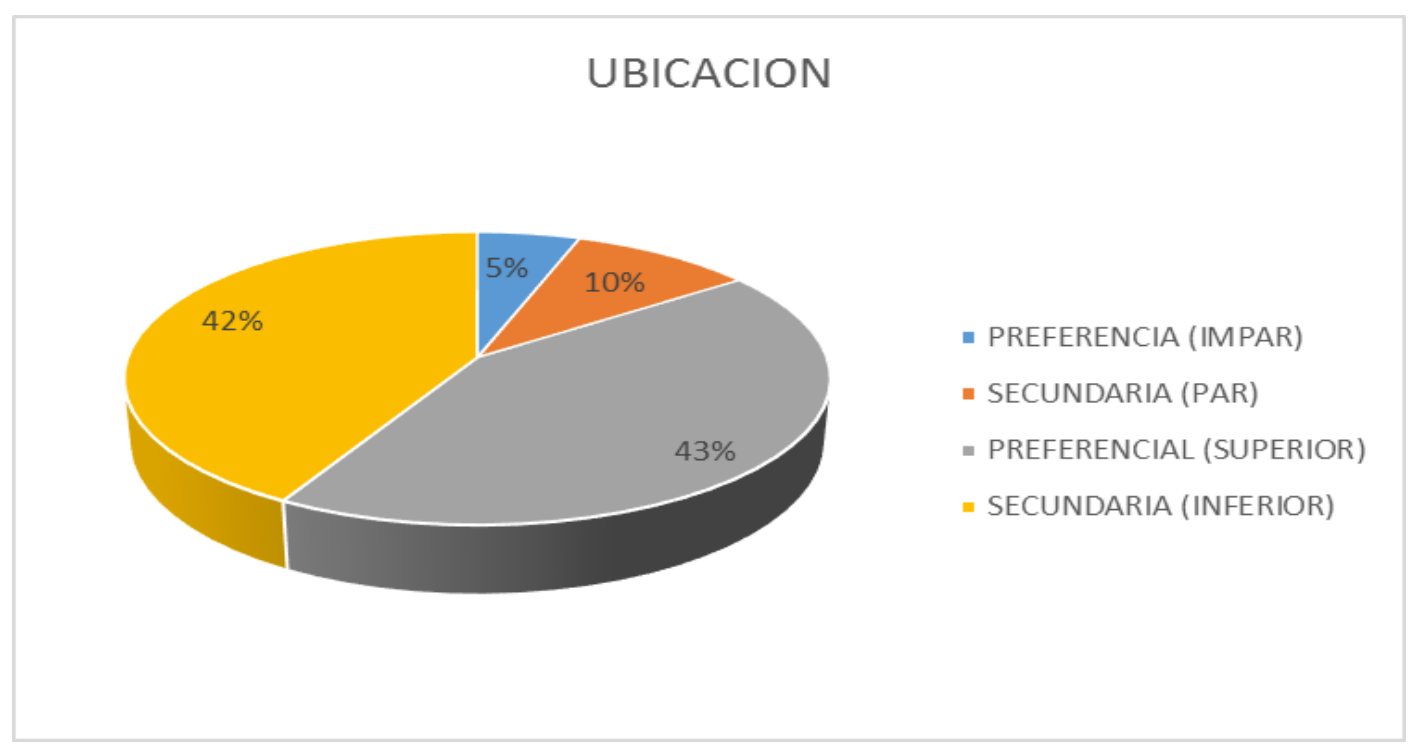

En Ambos periódicos las noticias se han colocado en la preferencial superior con el $43 \%$ le sigue la secundaria inferior con $42 \%$. 
G1

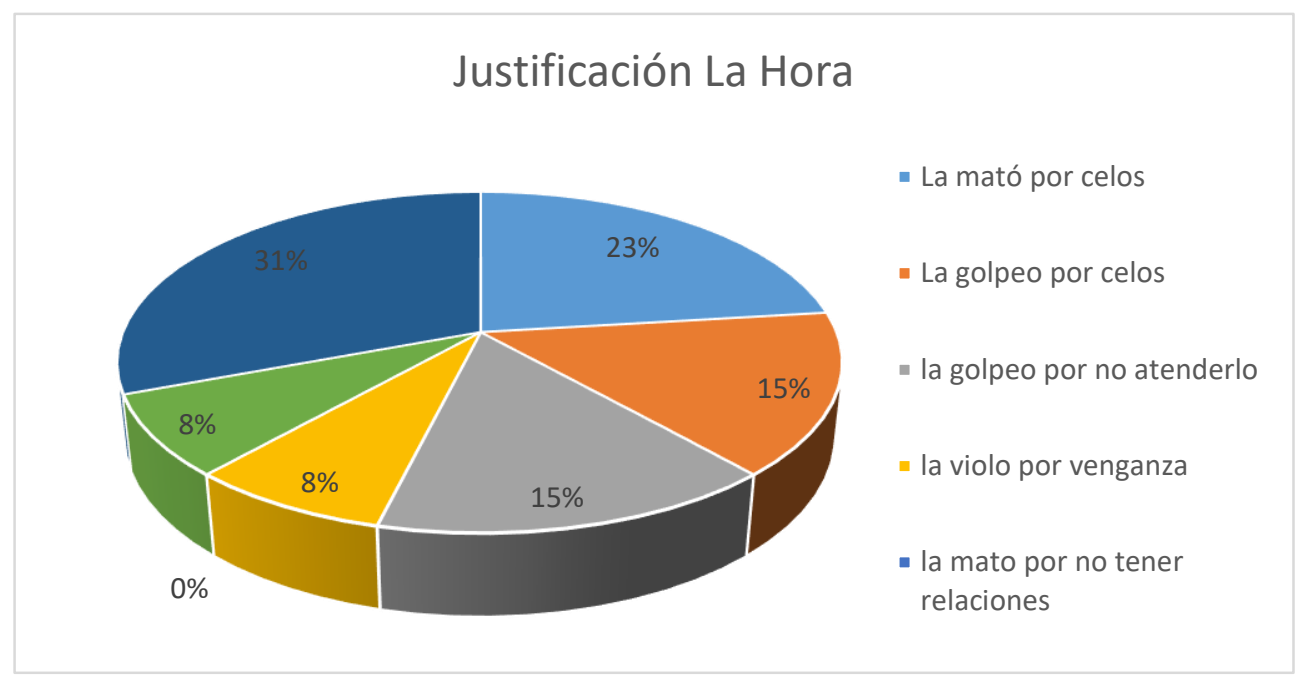

En las justificaciones se encontró que el $31 \%$ de los documentos se ha dado una violencia por razones que no son por golpiza o violación de conyugue sino más bien son robos y violaciones por personas externas.

G2

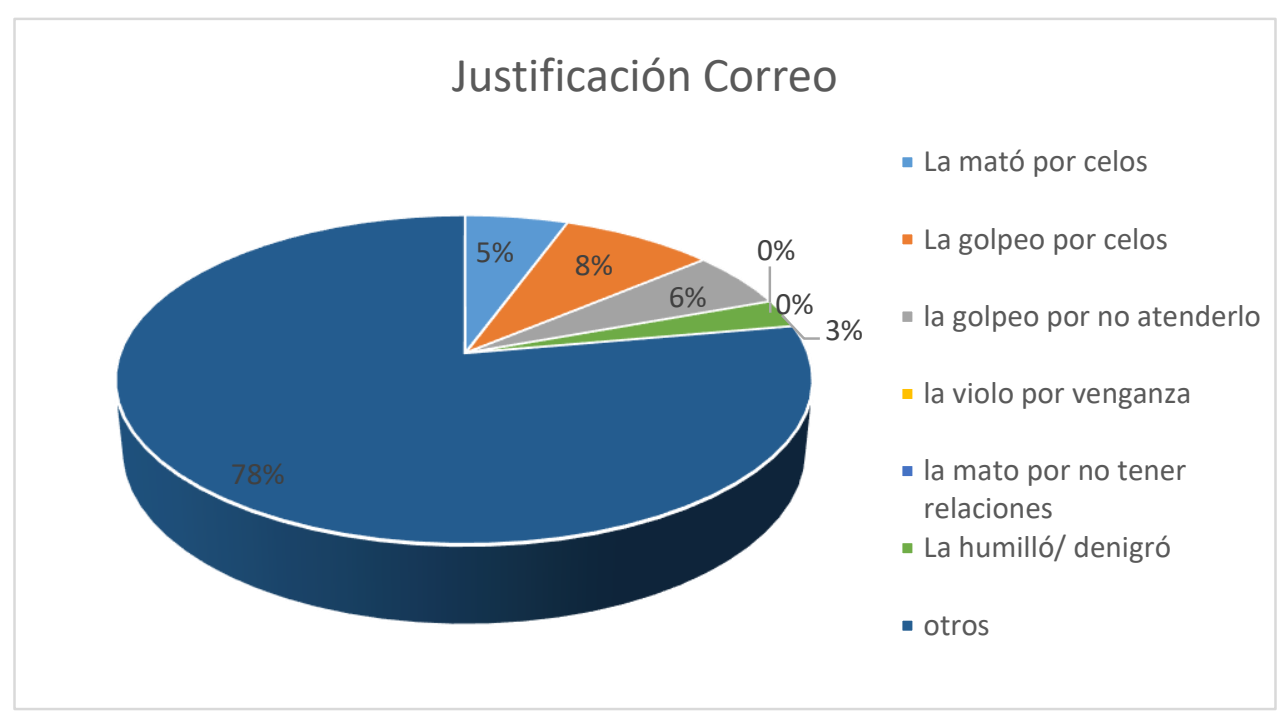

En el diario Correo se encontró que el 78\% de lo investigado se encuentra en la respuesta otro que considera que no es violencia por parte del conyugue sino más bien violencia en robos o violaciones por personas externas. 
G3

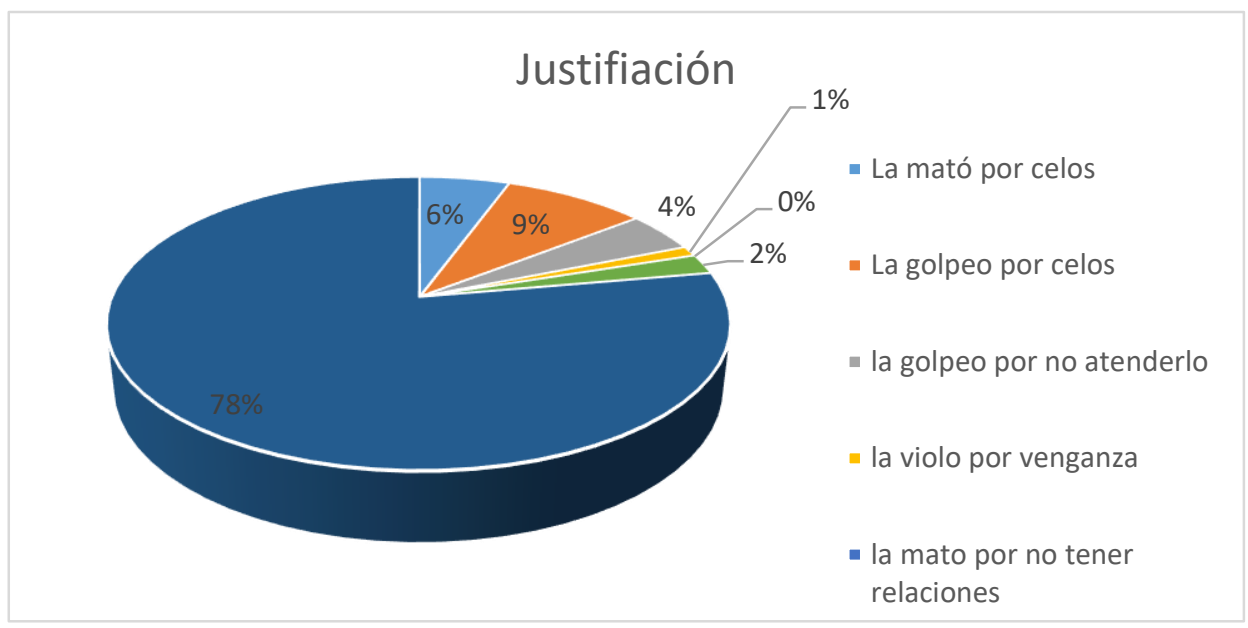

Considerando que la investigación es el tratamiento de la violencia a la mujer se consideró el ítem otros para el tipo de violencia sea por robos o violaciones que no se dan explícitamente por el conyugue así también se consideró otro tipo de acciones, la cual se llevó el $78 \%$ de lo estudiado.

\subsection{Discusión}

Estudios como este, señalan la importancia del buen manejo de información y el tratamiento de los contenidos periodísticos por parte de los responsables de escribir y publicar una nota periodística, ya que como lo refiere las Naciones Unidas, 2017: En los medios la capacitación y la sensibilización de los periodistas y otros profesionales de la comunicación que informan sobre la violencia contra la mujer constituyen prácticas prometedoras, mejoran la calidad de la información y favorecen creando conciencia y comprensión de las causas y consecuencias de la violencia contra la mujer por parte del público en general.

No obstante, los resultados de la presente investigación permitieron identificar las características del tratamiento informativo que se le está dando a las noticias de violencia contra las mujeres en la región Piura. Por ello, los primeros elementos que se tuvieron en cuenta fueron los concernientes a la cobertura e importancia, el hecho de que las notas periodísticas que presentan los diarios La Hora y Correo son de carácter sensacionalista tal como se plateó en la hipótesis. La noticias de violencia a la mujer son notas con tendencias al morbo para llamar la atención al lector, no existe una investigación de fuentes y en su mayoría son notas que no cuentan con el respectivo tratamiento periodístico, informan sobre el hecho pero no resaltan ni buscan llegar a la solución ante 
el abuso, un ejemplo son las noticias sobre los robos, en aquellas se da conocer el robo como hecho pero no lo describen como violencia o maltrato contra la mujer en el que dio el hecho, y si es denunciado solo se fija el hecho como robo pero no como violencia contra ella, es decir la leyes tampoco están sobreentendidas en cuanto a la violencia propiamente dicha.

Los tamaños más utilizados por el diario La Hora son el 1/2 página con el $33 \%$ y en el diario Correo la breve con $40 \%$ estos porcentajes muestran que ultimo diario mencionado solo menciona como breves es decir carecen de información y solo lanzan el hecho y lo que tiene en mano.

En las ubicaciones el diario La Hora coloca la noticia de modo secundario en la parte inferior que ocupó el $42 \%$ y el diario Correo superior con el 33\%, puesto que se presentan de manera que no ocupan un lugar adecuado para la visibilidad y aun así carece de información es decir no existe contraste de fuentes.

También se observó la coincidencia en cuanto a las formas de violencia presentadas en los diarios regionales. Así tenemos que en diario La Hora la violencia física tiene el mayor porcentaje $51 \%$, le sigue la sexual con el $23 \%$ y psicológica con el $22 \%$. En diario Correo se encontró la física con el $45 \%$, psicológica con el $28 \%$ y la sexual con el $27 \%$.

Para lo mencionado, citaré el siguiente ejemplo recopilado en diario La Hora (25/01/2016). Titular: Comerciante acuchilla a su esposa luego se suicida. Contenido: La mata por celos. Discusión por supuestos celos habría sido el detonante fatal entre la pareja de esposos.

-En esta noticia publicada en diario La Hora podemos observar la justificación que se le da al feminicidio: La mata por celos. En todo el contenido de la nota nunca se habla de una solución a semejante problemática, mucho menos se consulta con especialistas para tratar de reducir estos atentados contra la mujer.

Otro aspecto a resaltar sobre las representaciones que se hace de las mujeres agredidas en estas piezas periodísticas viene a ser el de cómo las mencionan en los titulares, ya que en lo observado se halló que al victimario prácticamente no se le menciona en los titulares y cuando lo hacen es para hacer saber que la mujer existe en función del varón, es decir, que hablan de relaciones de sometimiento, utilizando denominaciones y pronombres posesivos como "su expareja”, "su exnovio", "su esposo", “su compañero”, entre otros. 
Ahora, resulta esperanzador que el medio denomine a las víctimas en sus titulares como "mujer" o "mujeres" puesto que de esta forma se le está dando el enfoque de género haciéndolas valer ya no tanto por su edad, su ocupación o su estado civil.

De otra parte, encontramos que a las víctimas se les expone con más frecuencia que al victimario. En el caso de estas mujeres el medio da a conocer datos personales como la dirección de sus casas, lugar de trabajo o estudio, así mismo se menciona su edad, nombre y el nivel educativo, la edad por ejemplo se convierte para el medio en una variable clave de identificación puesto que con esta destacan los casos en los que la víctima es menor de edad y el agresor es significativamente mayor que ella, logrando con esta característica llamar la atención del lector.

Finalmente, no tenemos ningún mensaje esperanzador de alguna víctima que hable sobre cómo revertir esta situación de maltrato ni el apoyo y la protección que se puede recibir tras decidir denunciar al agresor.

\section{CONCLUSIÓN O CONSIDERACIONES FINALES}

- La intención con la que se ha llevado a cabo esta investigación no tiene que ver con alguna teoría conspiratoria o destructiva de los medios de comunicación analizados, sino por el contrario contribuir en la mejora de su formar de publicar las notas periodísticas sobre violencia hacia las mujeres desde una perspectiva de género. Algo que va más allá del hecho de informar sobre lo que pasa, para ser corresponsable junto a otras estructuras de socialización como la familia o la escuela de las visiones socialmente imperantes sobre el problema, debido a la selección sistemática que realizan de determinados enfoques, justificaciones, explicaciones y descripciones de las agresiones y sus protagonistas.

- Por lo mencionado, según los resultados encontrados, se concluye que en ambos diarios la violencia física es el tipo de agresión más usada por los agresores.

- Las notas periodísticas que presentan los diarios La Hora y Correo son de carácter sensacionalista con tendencias al morbo para llamar la atención del lector.

- Igualmente, no existe una investigación de fuentes y en su mayoría son notas que no cuentan con el respectivo tratamiento periodístico, informan sobre el hecho, pero no resaltan ni buscan llegar a la solución ante el abuso. Un claro ejemplo son las noticias sobre los robos hacia mujeres, en aquellas se da conocer el robo como hecho, pero no lo describen como violencia o maltrato contra la mujer, y si es denunciado solo se fija 
el hecho como robo, pero no como violencia contra ella, es decir las leyes tampoco están sobreentendidas en cuanto a la violencia propiamente dicha.

- Ambos diarios usan las noticias sobre violencia contra la mujer como un anzuelo para captar a los lectores; además, cumplen solo su rol informativo no hay una investigación y seguimiento de la noticia a fin de buscar o proponer alternativas de solución de esta problemática. Las noticias de violencia hacia la mujer más registradas en ambos diarios se produjeron en el mes de febrero.

- Los casos de violencia hacia la mujer provienen en su mayoría por robos, seguido de violaciones por familia o externos, entre otros.

- En este contexto, a violencia contra la mujer es todo acto de violencia de género que resulte, o pueda tener como resultado un daño físico, sexual o psicológico para la mujer, inclusive las amenazas de tales actos, la coacción o la privación arbitraria de libertad, tanto si se producen en la vida pública como en la privada.

- Finalmente, proponemos la utilización del manual de recomendaciones para mejorar el tratamiento periodístico de la violencia de la mujer.

\section{LISTA DE REFERENCIAS}

Abbott, L. (2016). Representación de la violencia contra la mujer. Washinton: Banco Interamericano de Desarrollo.

Aid, W. (2012). info@womensaid.ie. Recuperado el 15 de julio de 2016, de https://www.womensaid.ie/es/queeslaviolenciadomestica.html

Berganza, M., \& Chaparro, A. (05 de 04 de 2017). Hemeroteca Zer. Obtenido de Hemeroteca zER : http://www.ehu.eus/zer/hemeroteca/pdfs/zer32-02berganza.pdf

Burriel, J. (07 de 04 de 2017). No más violencia. Obtenido de No más violencia: http://nomasvg.com/para-asociaciones-y-profesionales/mitos-a-desmontar/

Cantera, L. (2005). La violencia doméstica. Barcelona: Universidad de Barcelona.

Cañada Martinez, I. (2002). La violencia contra la mujer como problema de salud. Servicio Territorial de Salud Pública, 2.

Cepal. (06 de 04 de 2017). Cepal. Obtenido de Cepal: http://repositorio.cepal.org/bitstream/handle/11362/40665/1/S1601000_es.pdf 
Dastres , c., \& Spencer, C. (05 de 04 de 2017). Universida de Chile. Obtenido de Universidad de Chile: https://www.cesc.uchile.cl/publicaciones/op_04_construccion.pdf

Diario Correo. (15 de 10 de 2016). Diario Correo. Obtenido de Diario Correo: http://diariocorreo.pe/edicion/piura/piura-mujer-no-soporto-los-golpespropinados-por-su-conviviente-y-fallecio-704722/

Diario el comercio. (05 de 07 de 2014). Diario el Comercio. Obtenido de Diario el Comercio: http://elcomercio.pe/sociedad/piura/edita-fue-masacrada-golpes-ymedicos-dejaron-morir-noticia- 1740817

Europrofem. (06 de 04 de 2017). Europrofem. Obtenido de Europrofem: http://www.europrofem.org/contri/2_05_es/cazes/03_cazes.htm

Fernandez Poncela, A. (2011). Prejuicios y estereotipos. Revista de antropología experimental, 328.

Fernández, A. (07 de 04 de 2017). Modulo deconstruir creencias y mitos. Obtenido de Modulo deconstruir creencias y mitos: http://www.rosario.gov.ar/sitio/verArchivo?id=5178\&tipo=objetoMultimedia

Fernandez, C. (2003). Violencia Doméstica. España: Ministerio de Sanidad y Consumo.

Fong, A., \& Triana, D. (05 de 04 de 2017). Universidad Autonoma de Occidente. Obtenido de Universidad Autonoma de Occidente: https://red.uao.edu.co/bitstream/10614/3413/1/TCS01154.pdf

Gamba, S. (06 de 04 de 2017). Mujeres en Red. Obtenido de Mujeres en Red: http://www.mujeresenred.net/spip.php?article1395

García Ruiz , J. (2000). El sexismo en el lenguaje. España: Minerva.

Gutierrez, M., Notario, B., Martinez, V., \& Monereo, F. (2009). Violencia contra la mujer en la prensa escrita. La Mancha: Ediciones de la Universidad de Castilla - La Mancha .

Lamas, M. (2007). Hablemos de Sexualidad.

Lamas, M. (2007). La perspectiva de género. Revista de Educación y Cultura, 76. Obtenido de http://www.psi.uba.ar/academica/carrerasdegrado/psicologia/sitios_catedras/elec tivas/816_rol_psicologo/material/unidad4/obligatoria/perspectiva_genero_lamas .pdf 
Llopis Susierra, M. (05 de 04 de 2017). Universidad Jaume. Obtenido de Universidad Jaume:

http://repositori.uji.es/xmlui/bitstream/handle/10234/98492/TFG_2014_LLOPIS M.pdf?sequence $=1$

López, P. (2002). Foro Nacional Mujer violencia y medios de comunicación. Madrid: Instituto de la Mujer.

Martinez, I. (06 de 04 de 2017). Universidad de Valencia. Obtenido de Universidad de Valencia: http://www.redhygeia.com/doc3.pdf

Méndez, N. G. (Junio, 2012). Violencia de Género. España: E.U.E Casa Salud Valdecilla. Menéndez Menéndez, M. I. (16 de 06 de 2013). Comunicación y Sociedad. Obtenido de Comunicación $\mathrm{y}$ Sociedad: http://www.comunicacionysociedad.cucsh.udg.mx/sites/default/files/a2_41.pdf

Montecino, S., \& Rebolledo, L. (2011). Conceptos de Género y desarrollo. (30; 32; 35). Montiel. (2014). Tratamiento de la violencia contra la mujer. Mexico: Universidad de Chile.

Mora Chamorro, H. (2008). Manual de protección a victimas de violencia doméstica. Alicante: Club universitario.

Morales Morante, F. (05 de 04 de 2017). Universidad Autónoma de España. Obtenido de Universidad Autónoma de España: http://www.correspondenciasyanalisis.com/es/pdf/v4/pe/4_analisis_tratamiento. pdf

Naciones Unidas. (08 de 04 de 2017). Naciones Unidas. Obtenido de Naciones Unidas: http://www.un.org/womenwatch/daw/public/VAW_Study/VAW-Spanish.pdf

Naciones Unidas y Derechos Humanos. (07 de 04 de 2017). Naciones Unidas. Obtenido de Naciones

Unidas: http://www.ohchr.org/SP/Issues/Women/WRGS/Pages/GenderStereotypes.aspx

Navarro, J. (17 de 09 de 2012). Diario Correo. Obtenido de Diario Correo: http://diariocorreo.pe/ciudad/correo-y-sus-50-anos-en-la-historia-de-piura232315/

Organización Mundial de la Salud. (05 de 04 de 2017). OMS. Obtenido de OMS: http://www.who.int/topics/gender/es/ 
Público. (05 de 04 de 2017). Público. Obtenido de Público: http://www.publico.es/sociedad/prensa-autocritica-tratamiento-violenciamachista.html

Ramirez Alvarado. (2003). Medios de Comunicación y Violencia contra la mujer. Sevilla: Instituto Andaluz de la Mujer.

Real Academia Española. (05 de 04 de 2017). Real Academia Española. Obtenido de Real Academia Española: http://dle.rae.es/?id=aWzrvDX

Revista Electrónica de Ciencia Penal y Criminología. (07 de 04 de 2017). Revista Electrónica de Ciencia Penal y Criminología. Obtenido de Revista Electrónica de Ciencia Penal y Criminología: http://criminet.ugr.es/recpc/recpc_02-07.html

Rodigou, M. (2007). La violencia hacia las mujeres en los medios de comunicación. Córdova: cicsa.

Rodriguez Carcela, R. (05 de 04 de 2017). Correspondencia y Análisis. Obtenido de Correspondencia $\mathrm{y}$ Análisis: http://www.correspondenciasyanalisis.com/es/pdf/pe/is.pdf

RPP noticias. (20 de 04 de 2017). RPP noticias. Obtenido de RPP noticias: http://rpp.pe/peru/actualidad/los-casos-de-feminicidio-en-peru-aumentaron-en2016-noticia-1019057 